\title{
Research on the Personal Quality of Chinese University Counselors
}

\author{
Wen Lan ${ }^{1, *}$, Yang Shaogang ${ }^{1}$, Deng Yanhong ${ }^{1}$ \\ ${ }^{1}$ South China Business College, Guangdong University of Foreign Studies, Guangzhou, Guangdong, China \\ *Email: windlives@163.com
}

\begin{abstract}
College counselors are important key members for ideological and political work in China. The quality of college counselors will directly affect the development of college students in all aspects. Most predecessors only conduct theoretical analysis on counselors' quality, which lacks the support of empirical research. Based on literature analysis and interviews, we took 880 Chinese college teachers and students as research objects, verified the reliability and validity of data, then conducted exploratory factor analysis (EFA) and confirmatory factor analysis (CFA), explored the structure of college counselors' personal quality. The results show that: (1) This test has strong reliability and validity. Cronbach's $\alpha$ coefficient in the total test and composite reliability $(\mathrm{CR})$ are all above 0.8 ; all factor loadings and AVE values are above 0.5. (2) The structure of Chinese college counselors' personal qualities is a 3-factor model: ability, attitude and discipline. The cumulative variance contribution rate of these three factors reached $63.68 \%$. (3) The 3 -factor model fitting indexes of CFA are all good. Conclusion: A 3-factor model of personal qualities, which include ability, attitude, discipline, is obtained in this research. These three factors are highly consistent with the requirements for counselors regulated in Order 43 of The Ministry of Education of the People's Republic of China Provisions on the Construction of Counselors in Regular Institutions of Higher Education, which require them to have "strong politics, excellent business, strict discipline and positive work style". This study has very important practical significance.
\end{abstract}

Keywords: College counselor; personal quality; China

\section{Issues Raised}

In China, college counselors are the organizers, implementers, and mentors in the daily ideological and political education and management of college students. Colleges and universities should insist on building the contingent of counselors as an important part of the construction of teachers and management teams. Counselors' personal quality refers to the overall quality of counselors to educate college students, deal with student affairs, guide student learning and life planning etc.

In Western universities and colleges, due to the differences of management institutions, there is no equivalent role of "counselor". Student work is called administration and leadership in student affairs, and the role function of its related administrative staff is similar to the college counselors in our country. The systematic study of student work can be first traced back to the theory proposed by Chickering in 1969. He makes requests to officers based on 7 vectors of student growth. They are: growth ability, emotion management, growth autonomy, identity establishment, interpersonal relationships, purpose clarification, and growth integrity (Leila V. Moore, M. Lee Upcraft, 1990). In 20th century, American universities general divide "counselors" into 5 categories according to their professional qualities: psychological counselors, vocational counselors, learning counselors, life counselors and accommodation counselors (Yan Ping, 2006).

Since China's "Counselor System" was proposed by President Jiang Nanxiang of Tsinghua University in 1953. The system has already had a history of more than 50 years, and it was called as "political guidance counselor" earlier. The system aims at establishing an ideological and political work team among teachers and students, and ensuring the leadership of the party (CCP) over universities. The research on college counselors' traits originated from the key words "quality" or "competency", the classification of traits had multiple dimensions, and the others are "ability", "occupational competence" and "literacy". But most previous studies only analyzed in theory (Leila V. Moore, M. Lee Upcraft, 1990). Some of the research 
methods were highly subjective. However, there were few empirical studies on the investigation and mathematical analysis.

\section{Investigation Process}

This survey took Chinese college teachers and students as research objects. The questionnaires were based on Likert 7 point scale. SPSS 22.0 and AMOS 21.0 were applied to data analysis and processing. Then data were verified for the reliability and validity, conducted correlation analysis, exploratory factor analysis (EFA), confirmatory factor analysis (CFA).

\section{$3 \quad$ Research 1: Preparation and Pretest of Questionnaire}

\subsection{Procedure}

On the basis of drawing on the above research results, this study adopted the questionnaire method to do research in 2017. First of all, the interview method was used to interview college teachers and students individually. 5-8 words and phrases about personal qualities of counsellor were listed; the frequencies of key words were counted and 64 summary items were selected. Besides, statements were organized to explain each item. All these contents formed the pretest questionnaire for College Counselor Quality Questionnaire.

The pretest questionnaire was based on Likert 7 point scale $(1=$ strongly disagree, $7=$ strongly agree $)$. The correlation coefficient between each item in the questionnaire and the total score was calculated. After deleting the item of the correlation coefficient $\mathrm{r}<0.4$, when the questionnaire contained 51 questions, EFA showed that 9 factors were extracted and the cumulative variance contribution rate reached $82.83 \%$. The model tended to be stable. Three lie detection questions were compiled by drawing on the MMPI lie scale, which formed a formal questionnaire of "college counselors' quality" with 54 items.

\subsection{Research Object}

Stratified sampling method is used to select subjects from related teachers and university students to conduct formal testing. 800 questionnaires were issued and 696 questionnaires were collected. There were 537 valid questionnaires after the lie detection screening was done. The average age of subjects was 20.16 \pm 2.07 years. There were 106 males and 431 females. 40 teachers (24 undergraduate and 16 graduate) as well as 497 students (207 freshmen, 121 sophomores, 105 juniors and 64 seniors) were selected.

\subsection{Results Analysis}

\subsubsection{Exploratory Factor Analysis (EFA)}

First of all, the lie detection questions were deleted, and then the correlation between the remaining 51 questions and total score was calculated. There was no question with the correlation index of lower than 0.4. Therefore, Exploratory Factor Analysis (EFA) was done to 51 items.

The analysis result of KMO and Barrlett spherical test coefficient shows that the index of sample fitness coefficient KMO is 0.979 , which is a very suitable data for factor analysis. Barrlett's test of spherical is $23516.560 \mathrm{df}$ is 1275 , and $P<0.001$. The spherical assume is rejected, indicating that the questionnaire items are not independent and the values are valid. EFA use principal component analysis and rotation is varimax, eigenvalue is over 1 , and the number of factor is not limited. When five factors are formed by factor rotation, the cumulative variance has reached $65.72 \%$. All 51 items enter the EFA model. Factor analysis results showed that the factor loading value and the common factor variance of 51 items were all larger than 0.3. Therefore, no items were deleted and all of them were selected into the EFA. The variance explained of each item can be seen in Table 1 . So, based on the contents of the items, we named these 5 factors: Moral quality, Business execution, Political consciousness, Guiding strategy and Interpersonal coordination. 
Table1. Results of EFA $(\mathrm{n}=537)$

\begin{tabular}{|c|c|c|c|}
\hline Factor & Items (Factor loading) & Eigenvalue & $\begin{array}{c}\text { Variance } \\
\text { contribution rate }\end{array}$ \\
\hline Moral quality & $\begin{array}{lllllr}\text { Q3(0.75) } & \text { Q5(0.74) } & \text { Q7(0.72) } & \text { Q2(0.67) } & \text { Q6(0.67) } & \text { Q1(0.66) } \\
\text { Q15(0.65) } & \text { Q10(0.58) } & \text { Q8(0.57) } & \text { Q9(0.56) } & \text { Q14 }(0.54) & \text { Q24(0.51) } \\
\text { Q11(0.50) } & \text { Q28(0.45) } & \text { Q4(0.42) } & & & \\
\end{array}$ & 27.20 & $18.02 \%$ \\
\hline $\begin{array}{l}\text { Business } \\
\text { execution }\end{array}$ & $\begin{array}{l}\text { Q35(0.67) Q34(0.64) Q46(0.64) Q37(0.61) Q36(0.60) Q45(0.58) } \\
\text { Q39(0.56) Q29(0.55) Q44(0.54) Q42(0.54) Q47(0.52) Q30(0.52) } \\
\text { Q20(0.52) Q32(0.47) }\end{array}$ & 2.47 & $15.79 \%$ \\
\hline $\begin{array}{l}\text { Political } \\
\text { consciousness }\end{array}$ & $\begin{array}{l}\text { Q31(0.76)Q17(0.75) Q48(0.73) Q41(0.63) Q40(0.56) Q26(0.53) } \\
\text { Q23(0.49) Q18(0.49) Q12(0.46) }\end{array}$ & 1.44 & $14.63 \%$ \\
\hline Guiding strategy & $\begin{array}{l}\text { Q51(0.69) Q53(0.62) Q54(0.56) Q43(0.52) Q52(0.49) Q49(0.40) } \\
\text { Q38(0.40) }\end{array}$ & 1.07 & $8.73 \%$ \\
\hline $\begin{array}{l}\text { Interpersonal } \\
\text { coordination }\end{array}$ & Q13(0.57) Q21(0.52) Q22(0.50) Q25(0.44)Q27(0.41) & 1.03 & $7.96 \%$ \\
\hline
\end{tabular}

\subsubsection{Test Reliability}

Cronbach's $\alpha$ coefficient and the split-half reliability coefficient in the total test are all above 0.9 , indicating that the actual value is in good agreement with the true value. The internal $\alpha$ coefficients and the split-half reliability coefficient of the five factors are all above 0.8 . The reliability coefficient indicates that this test is good job.

Table 2. Test reliability

\begin{tabular}{llll}
\hline Factor & Number of item & Cronbach's $\alpha$ coefficient & Split-half reliability \\
\hline Moral quality & 15 & 0.95 & 0.93 \\
Business execution & 14 & 0.96 & 0.95 \\
Political consciousness & 10 & 0.93 & 0.90 \\
Guiding strategy & 7 & 0.87 & 0.85 \\
Interpersonal coordination & 5 & 0.85 & 0.86 \\
Total test & 51 & 0.98 & 0.95 \\
\hline
\end{tabular}

\section{Research 2: Revised Questionnaire}

\subsection{Research Object}

As the above research objects were only from Guangdong province and cannot represented the whole of China. Furthermore, the author wanted to reduce the questionnaire items contained in the model. So, in 2018, we increased the number of research objects which were from Guangdong, Hunan, Guizhou, Heilongjiang and other regions' universities and colleges. We expanded the sample size to verify the questionnaire and modify the model. 1340 questionnaires were issued and 1137 questionnaires were collected. There were 880 valid questionnaires after the lie detection screening was done. Of these, 780 students were enrolled. The average age of students was $19.72 \pm 1.30$ years. 157 boys, 623girls; 170 freshmen, 299 sophomores, 131 juniors and 180 seniors.100 teachers were selected, the average age of them was $32.63 \pm 8.83,39$ males and 61 females; 53 undergraduate and 47 graduate.

\subsection{Research Tools}

A questionnaire named "college counselors' quality" with 54 items (included 3 lie detection questions). The questionnaires were used Likert 7 point scale $(1=$ strongly disagree, $7=$ strongly agree). SPSS 22.0 and AMOS 21.0 were applied to data analysis and processing. 


\subsection{Results and Analysis}

\subsubsection{Item Analysis}

Item analysis was carried out on the questionnaire $(n=880)$. The correlation coefficient of all 51 items and the total score was above $0.5(\mathrm{r}>0.5)$, and $P<0.001$. The coefficient of groups with low scores $(27 \%)$ was significantly lower than that of groups with high scores $(27 \%)$.

Table 3. Loading matrix after factor rotation $(n=880)$

\begin{tabular}{|c|c|c|c|c|c|}
\hline \multicolumn{2}{|l|}{ Ability } & \multicolumn{2}{|l|}{ Attitude } & \multicolumn{2}{|l|}{ Discipline } \\
\hline Items & $\begin{array}{l}\text { Factor } \\
\text { loading }\end{array}$ & Items & $\begin{array}{l}\text { Factor } \\
\text { loading }\end{array}$ & Items & $\begin{array}{l}\text { Factor } \\
\text { loading }\end{array}$ \\
\hline Q45 Practice ability & 0.72 & Q3 Respect students & 0.82 & Q17 Support Party (CCP) & 0.83 \\
\hline Q47 Innovation & 0.69 & Q7 Justice and equity & 0.77 & Q31 Love motherland & 0.76 \\
\hline Q35 Coordination & 0.69 & Q1 Sincerity & 0.75 & Q48 Familiar with party affairs & 0.74 \\
\hline Q36 Investigate ability & 0.68 & Q2 Work passion & 0.71 & Q16 Observe rules & 0.67 \\
\hline Q46 Strain ability & 0.68 & Q5 Reliable & 0.70 & Q41 Love school & 0.57 \\
\hline Q29 Observation & 0.65 & Q6 Approachable & 0.67 & Q12 Political sense & 0.55 \\
\hline Q52 Career planning & 0.65 & Q15 Empathy & 0.67 & Q18 Cultivate students & 0.55 \\
\hline Q34 Leadership & 0.65 & Q14 Civilized & 0.58 & & \\
\hline Q42 Confidence & 0.64 & Q10 Influential & 0.57 & & \\
\hline Q25 Expression ability & 0.64 & Q11 Emotional stability & 0.56 & & \\
\hline Q54 Organizational capacity & 0.64 & Q8 Rational & 0.52 & & \\
\hline Q30 Time management & 0.63 & & & & \\
\hline Q43 Foreign language ability & 0.62 & & & & \\
\hline Q28 Decisive & 0.61 & & & & \\
\hline Q27 Humanistic quality & 0.61 & & & & \\
\hline $\begin{array}{l}\text { Q26 Ideological and political } \\
\text { knowledge }\end{array}$ & 0.61 & & & & \\
\hline Q32 Introspection & 0.59 & & & & \\
\hline Q51 communication skills & 0.59 & & & & \\
\hline Q13 Compressive ability & 0.56 & & & & \\
\hline Q21 Patient & 0.52 & & & & \\
\hline Number of item & 20 & 11 & & 7 & \\
\hline Eigenvalue & 20.86 & 2.01 & & 1.33 & \\
\hline Variance contribution rate & $54.89 \%$ & $5.30 \%$ & & $3.49 \%$ & \\
\hline
\end{tabular}

\subsubsection{Exploratory Factor Analysis(EFA)}

The analysis result of KMO and Barrlett spherical test coefficient shows that the index of sample fitness coefficient KMO is 0.982 . Barrlett's test of spherical is 38902.292 , df is 1275 , and $P<0.001$, which is a very suitable data for factor analysis.

Since the factor loadings of some items on each factor were lower than 0.5 or high loadings existed simultaneously on multiple factors, we deleted inappropriate items and conducted factor analysis again. After 12 questions were deleted, three factors whose eigenvalues $>1$ were extracted from the remaining 38 questions, and the total explained variance was $63.68 \%$. The maximum factor loading of all questions was above 0.5 , and only one factor had high loading. Each factor was named according to the connotation of items. Items of factor 1 involved various abilities of counselors in their work, therefore, it was named as "abilities".Items of factor 2 involved counselors' attitude towards students in their work, therefore, it was named as "attitude". Items of factor 3 mainly included counselors' standpoints on party, nation and laws, therefore, it was named as "discipline". Refer to Table 3 for details.

\subsubsection{Validity and Reliability}

Cronbach's $\alpha$ coefficients, CR, AVE and the factor loading of each item of these 3 factors are shown in table 4 . The results in the table showed that Cronbach's $\alpha$ coefficients and CR were 0.8 , and both above 0.7 , indicating good reliability. All factor loadings and AVE were above 0.5, indicating good validity. 
Table 4. Main results of reliability and validity

\begin{tabular}{llll}
\hline Factor & Cronbach's $\alpha$ coefficients & AVE & CR \\
\hline Ability & 0.97 & 0.60 & 0.97 \\
Attitude & 0.94 & 0.56 & 0.93 \\
Discipline & 0.90 & 0.53 & 0.89 \\
\hline
\end{tabular}

\subsubsection{Confirmatory Factor Analysis(CFA)}

Software AMOS21.0 was used to do CFA. Main fitting indexes of the two models all reached the recommended range: before the questionnaire was revised (five-factor model) and after the questionnaire was revised (three-factor model), so both models can be used. Among fitting indexes measuring the model, $X^{2} / d f$ of the model smaller than 5 meant that the model could be accepted. If $X^{2} / d f$ of the model was smaller than 3, the model would be well fitted. The closer the GFI, AGFI, NFI, CFI, and IFI are to 1, the better the fitness is. The closer RMSEA is to 0 , the better the result is, the critical criterion is 0.08 . In addition, there was also a single-factor model without extracting principal component factor. Comprehensive comparison showed that (see table 5) the revised three-factor model had better data fitting degree, which meant that better statistical indicators would be shown after the questionnaire was revised.

Table 5. CFA model fitting indexes

\begin{tabular}{llllllllll}
\hline & $X^{2}$ & $d f$ & $X^{2} / d f$ & GFI & AGFI & NFI & CFI & IFI & RMSEA \\
\hline One-Factor Model & 5650.89 & 1224 & 4.617 & 0.627 & 0.595 & 0.768 & 0.808 & 0.808 & 0.082 \\
Five-Factor Model & 4411.32 & 1214 & 3.634 & 0.735 & 0.710 & 0.819 & 0.861 & 0.862 & 0.070 \\
Three-Factor Model & 2399.55 & 629 & 3.815 & 0.871 & 0.848 & 0.916 & 0.936 & 0.937 & 0.057 \\
\hline
\end{tabular}

The structural equation model (SEM) of counselor's personal quality is shown in figure 1. The load of observation variables on the corresponding latent variables exceed 0.6 , indicating that each observation variable has a large interpretation rate for the underlying latent variables. Observation variables loaded on the residuals are less than 0.5 . The relationship between variables is more reliable and the questionnaire has a good structural validity.

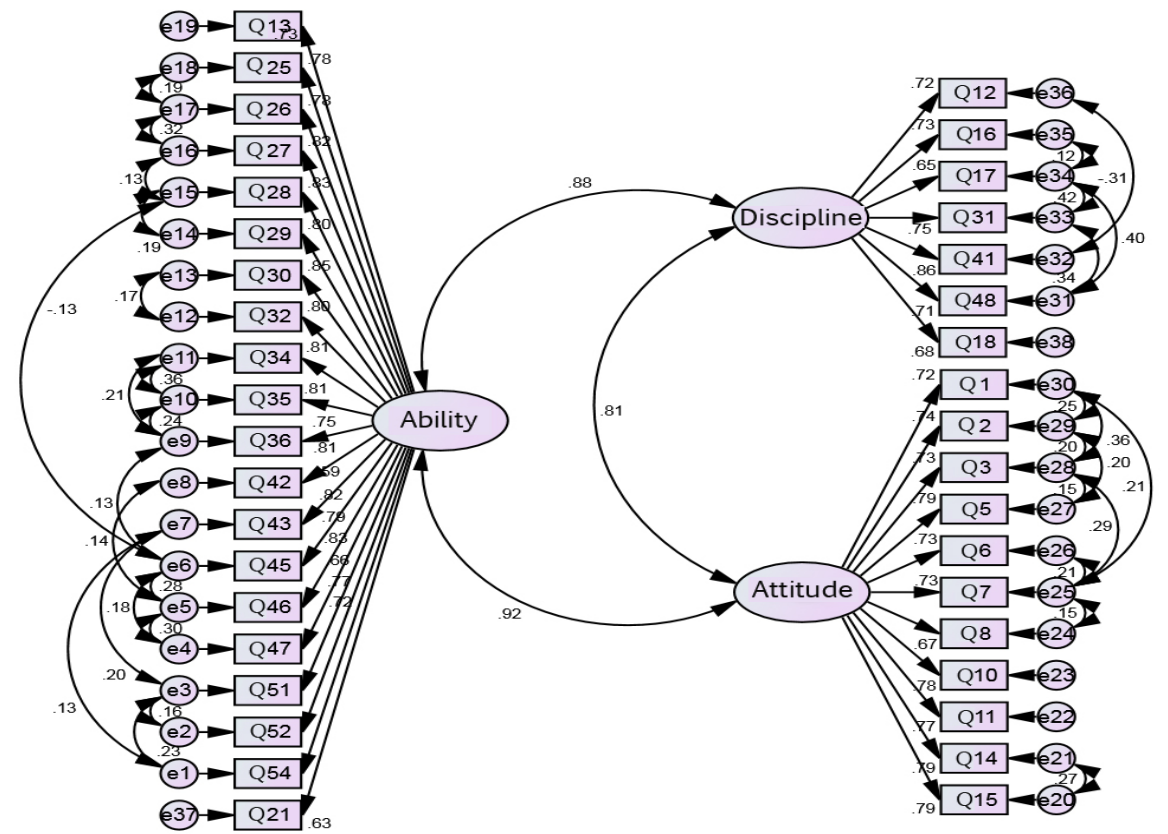

Figure 1. Three-Factor Model of Chinese college counselors' personal quality (SEM) 


\section{Discussion}

A 3-factor model of personal qualities, which include ability, attitude, discipline, is obtained in this research. These three factors are highly consistent with the requirements for counselors regulated in Order 43 of The Ministry of Education of the People's Republic of China Provisions on the Construction of Counselors in Regular Institutions of Higher Education, which require them to have "strong politics, excellent business, strict discipline and positive work style". Among them, "Ability" specifically refers to necessary skills of counselors in handling daily affairs, which involve management, coordination, communication, expression, leadership, practice, organization and other abilities. "Attitude" specifically refers to the emotional interaction between counselors and students in their work and life. They can guide students' values through words and deeds. "Discipline" means that the counselor, as a member of the communist party, shall have firm and correct standpoints and world views on being faithful to the Party and loving the country.

This 3-factor model reflects college teachers and students' evaluation on qualities of counselors and they display changes in their demands for career roles according to the development of the times. On the one hand, college teachers and students have requirements on counselors' various affairs and organizational management ability. On the other hand, they require that counselors shall have stern discipline, set a good example for students through their deeds and words so as to help students form correct values and outlooks on life. In addition, they emphasize that counselors should have a high political consciousness, be familiar with party affairs work and university regulations, and ensure that various management can be carried out in accordance with laws and regulations. The affairs of college counselors covers a wide range of aspects, including party affairs of students, student communities and associations, awards and attendance loans, school roll affairs (suspension or dropping out of school), graduation and employment, student behaviors management, dormitory management and so on. As for management nature, their work can be divided into student organization management and guidance, student enrolment management for university autonomy, authorized or entrusted education administration management and civil affairs management for civil subjects (Li Hua, 2014).

There is no fixed structure in the classification of vocational qualities and there are overlapping parts in the previous researches on college counselors' competence characteristic groups, vocational abilities and quality accomplishment. Western universities emphasize the administrator, leadership and education ability of student affairs management. However, in China, people lay emphasis on their ideological and political morality, professional knowledge guidance, and transferable skills for organizing, coordinating, serving and promoting student development as well as their personal mental health. An essential requirement for the professionalization of counselors is its long-term feature, continuity, stability and extensive social identity. With the basic features of stability and long-term, counselor becomes a stable and long-term role. Only then can we talk about the issue of their professionalization (Zhu Ping, 2007), because this issue is beneficial for correctly positioning the relationship between counselors and students, implementing the scientific quantifying of moral education in universities and improving the overall quality of counselors.

Acknowledgements. The article is supported by 2017 Guangdong education science "13th five-year plan" moral education project (Code Number: 2017JKDY16); 2017 Guangdong high education Grant of Special Creativity (Humanities and social science) Young Creative talents project (Code Number: 2017WQNCX208); 2016 Guangdong Philosophy and social science "13th five-year plan" project (Code Number: GD16XJY31).

\section{References}

1. Leila V.Moore, M. Lee Upcraft. Theory in Student Affairs:Evolving Perspectives [J]. NEW DIRECTIONS FOR STUDENT SERVICES.1990,51:3-23.

2. Yan Ping. Comparison of The Work of College Instructors in China and The United States -- A Brief Discussion on the Development Direction of China's College Counselor System[J]. Journal of Huna Mass Media Vocational Technical College, 2006(7): 115- 116. 
3. Lan Haitao; Wei Xing. The Quality and Ability Structure of College Counselors and Their Training Methods[J]. China Higher Education, 2017,5:42-44.

4. Li Hua. On the Plight of Dual Role of University Counselors and Its Coordinated Path[J]. Journal of Sichuan Normal University ( Social Sciences Edition), 2014,41(6):71-77.

5. Zhu Ping. Interpretation of College Instructor' s Professionalization and Specialization[J]. Journal of Anhui Normal University(Humanities and Social Sciences), 2007,35(2):218-223.

\section{Appendix section:}

\section{"College counselors' quality" questionnaire}

Hello!

Thank you very much for your time to help us complete this survey! Please answer the following questions according to your real thoughts. The information you have filled out is very important to our research. Please answer every question. Don't miss it. We only do holistic analysis, not case studies. We promise to keep your personal information strictly confidential. Please feel free to fill it out. Thank you for your participation and support in our research!

What do you think the counselor's personal qualities should include? According to your view of the following items, assess the score 1-7, 1 (strongly disagree) - > 7 points (strongly agree):

\begin{tabular}{|c|c|c|c|c|c|c|c|c|c|c|c|c|c|c|c|c|c|}
\hline 1 & Sincerity & 1 & 2 & 3 & 4 & 5 & 6 & 7 & 28 & Decisive & 1 & 2 & 3 & 4 & 5 & 6 & 7 \\
\hline 2 & Work passion & 1 & 2 & 3 & 4 & 5 & 6 & 7 & 29 & Observation & 1 & 2 & 3 & 4 & 5 & 6 & 7 \\
\hline 3 & Respect students & 1 & 2 & 3 & 4 & 5 & 6 & 7 & 30 & Time management & 1 & 2 & 3 & 4 & 5 & 6 & 7 \\
\hline 4 & Prestige & 1 & 2 & 3 & 4 & 5 & 6 & 7 & 31 & Love motherland & 1 & 2 & 3 & 4 & 5 & 6 & 7 \\
\hline 5 & Reliable & 1 & 2 & 3 & 4 & 5 & 6 & 7 & 32 & Introspection & 1 & 2 & 3 & 4 & 5 & 6 & 7 \\
\hline 6 & Approachable & 1 & 2 & 3 & 4 & 5 & 6 & 7 & 33 & $\begin{array}{l}\text { Not according to } \\
\text { instructions }(\mathrm{L})\end{array}$ & 1 & 2 & 3 & 4 & 5 & 6 & 7 \\
\hline 7 & Justice and equity & 1 & 2 & 3 & 4 & 5 & 6 & 7 & 34 & Leadership & 1 & 2 & 3 & 4 & 5 & 6 & 7 \\
\hline 8 & Rational & 1 & 2 & 3 & 4 & 5 & 6 & 7 & 35 & Coordination & 1 & 2 & 3 & 4 & 5 & 6 & 7 \\
\hline 9 & Rigorous & 1 & 2 & 3 & 4 & 5 & 6 & 7 & 36 & Investigate ability & 1 & 2 & 3 & 4 & 5 & 6 & 7 \\
\hline 10 & Influential & 1 & 2 & 3 & 4 & 5 & 6 & 7 & 37 & Optimistic & 1 & 2 & 3 & 4 & 5 & 6 & 7 \\
\hline 11 & Emotional stability & 1 & 2 & 3 & 4 & 5 & 6 & 7 & 38 & Forgive & 1 & 2 & 3 & 4 & 5 & 6 & 7 \\
\hline 12 & Political sense & 1 & 2 & 3 & 4 & 5 & 6 & 7 & 39 & Set the example & 1 & 2 & 3 & 4 & 5 & 6 & 7 \\
\hline 13 & $\begin{array}{l}\text { Compressive } \\
\text { ability }\end{array}$ & 1 & 2 & 3 & 4 & 5 & 6 & 7 & 40 & Legal knowledge & 1 & 2 & 3 & 4 & 5 & 6 & 7 \\
\hline 14 & Civilized & 1 & 2 & 3 & 4 & 5 & 6 & 7 & 41 & Love school & 1 & 2 & 3 & 4 & 5 & 6 & 7 \\
\hline 15 & Empathy & 1 & 2 & 3 & 4 & 5 & 6 & 7 & 42 & Confidence & 1 & 2 & 3 & 4 & 5 & 6 & 7 \\
\hline 16 & Observe rules & 1 & 2 & 3 & 4 & 5 & 6 & 7 & 43 & Foreign language ability & 1 & 2 & 3 & 4 & 5 & 6 & 7 \\
\hline 17 & $\begin{array}{l}\text { Support } \\
\text { Party }(\mathrm{CCP}) \\
\end{array}$ & 1 & 2 & 3 & 4 & 5 & 6 & 7 & 44 & Communication skills & 1 & 2 & 3 & 4 & 5 & 6 & 7 \\
\hline 18 & Cultivate students & 1 & 2 & 3 & 4 & 5 & 6 & 7 & 45 & Practice ability & 1 & 2 & 3 & 4 & 5 & 6 & 7 \\
\hline 19 & Harsh ( L ) & 1 & 2 & 3 & 4 & 5 & 6 & 7 & 46 & Strain ability & 1 & 2 & 3 & 4 & 5 & 6 & 7 \\
\hline 20 & Concern & 1 & 2 & 3 & 4 & 5 & 6 & 7 & 47 & Innovation & 1 & 2 & 3 & 4 & 5 & 6 & 7 \\
\hline 21 & Patient & 1 & 2 & 3 & 4 & 5 & 6 & 7 & 48 & $\begin{array}{l}\text { Familiar with party } \\
\text { affairs }\end{array}$ & 1 & 2 & 3 & 4 & 5 & 6 & 7 \\
\hline 22 & Office skills & 1 & 2 & 3 & 4 & 5 & 6 & 7 & 49 & Love the work & 1 & 2 & 3 & 4 & 5 & 6 & 7 \\
\hline 23 & Executive force & 1 & 2 & 3 & 4 & 5 & 6 & 7 & 50 & Control others(L) & 1 & 2 & 3 & 4 & 5 & 6 & 7 \\
\hline 24 & Responsibility & 1 & 2 & 3 & 4 & 5 & 6 & 7 & 51 & Communication skills & 1 & 2 & 3 & 4 & 5 & 6 & 7 \\
\hline 25 & Expression ability & 1 & 2 & 3 & 4 & 5 & 6 & 7 & 52 & Career planning & 1 & 2 & 3 & 4 & 5 & 6 & 7 \\
\hline 26 & $\begin{array}{l}\text { Ideological and } \\
\text { political knowledge }\end{array}$ & 1 & 2 & 3 & 4 & 5 & 6 & 7 & 53 & Overall consciousness & 1 & 2 & 3 & 4 & 5 & 6 & 7 \\
\hline 27 & Humanistic quality & 1 & 2 & 3 & 4 & 5 & 6 & 7 & 54 & Organizational capacity & 1 & 2 & 3 & 4 & 5 & 6 & 7 \\
\hline
\end{tabular}


55. Gender: Male/Female

56. Age:

57. Identity:

A. Students

B. College counselors and student staff

C. College staff (except students' staff)

D. Other social workers

End 